\title{
Substituição do Milho pela Farinha de Varredura de Mandioca (Manihot esculenta Crantz) em Rações de Ovinos: Consumo, Digestibilidade, Balanços de Nitrogênio e Energia e Parâmetros Ruminais
}

\author{
Lúcia Maria Zeoula1, Saul Ferreira Caldas Neto, ${ }^{3,5}$, Luiz Juliano Valério Geron², Emilyn Midore \\ Maeda ${ }^{4}$, Ivanor Nunes do Prado ${ }^{1}$, Paulo Henrique Moura Dian ${ }^{4}$, João Ricardo Vieira Jorge ${ }^{3}$, \\ Jair de Araújo Marques 6
}

\begin{abstract}
RESUMO - Avaliaram-se os efeitos dos níveis de substituição do milho (MI) pela farinha de varredura de mandioca (FV) (25, 50, 75 e $100 \%$ ) em rações para ovinos, sobre consumo voluntário, digestibilidade total dos nutrientes, balanços de nitrogênio (BN) e de energia (BE), $\mathrm{pH}$ e concentração de nitrogênio amoniacal $\left(\mathrm{N}-\mathrm{NH}_{3}\right)$ do líquido ruminal. Foram utilizados quatro carneiros machos, castrados, sem raça definida, com peso médio de $41,4 \mathrm{~kg}$ de peso vivo em um ensaio de digestibilidade utilizando o método de coleta total de fezes e urina. Os animais foram mantidos em gaiolas metabólicas, distribuídos em delineamento experimental quadrado latino 4x4. O líquido ruminal foi obtido por meio de sonda esofágica, nos tempos de zero, 2, 4, 6 e 8 horas após à alimentação da manhã. Não houve efeito dos níveis de substituição para os consumos de matéria seca (MS), matéria orgânica (MO), fibra em detergente neutro (FDN), energia e nitrogênio (N), para os coeficientes de digestibilidade da MS, MO, PB, FDN, amido e energia bruta (EB), e para o BN e os teores de NDT. O consumo de amido e EB apresentaram efeito quadrático crescente até o nível de $75 \%$ de FV na ração. A concentração de N amoniacal e o pH do líquido ruminal não diferiram em função do nível de substituição do MI pela FV. Concluindo-se que a FV pode substituir totalmente o MI nas rações de ovinos.
\end{abstract}

Palavras-chave: balanço de nitrogênio, consumo, digestibilidade, farinha de varredura de mandioca, milho, ovinos

\section{Cassava By-Product Flour Replacing Corn in Ration for Sheep: Intake, Digestibility, Nitrogen and Energy Balances and Ruminal Parameters}

\begin{abstract}
This work was carried-out to study the effect of substitution levels of corn (COR) by cassava by-product flour (CPF) $(25,50,75$ and $100 \%)$ in the ration for sheep on voluntary intake, nutrients apparent digestibility and nitrogen (NB) and energy (EB) balance, $\mathrm{pH}$ and ammonia concentration $\left(\mathrm{N}-\mathrm{NH}_{3}\right)$ in ruminal liquid. Four male, castrated sheep, without defined race, with medium weight of $41.4 \mathrm{AW}$, in trial of digestibility were used, using the method of total collect feces and urine. The animals were kept in cages of metabolism in $4 \times 4$ latin square design. The ruminal liquid was obtained by means of probe esofagic in the times $0,2,4,6$ and 8 hours (after feeding). There was no effect of substitution levels on intake of dry matter (DM), organic matter (OM), neutral detergent fiber (NDF), energy and nitrogen (N) and for apparent digestibility of DM, OM, CP, NDF, starch and gross energy (GE) and for NB and TDN levels. The intake of starch and GE presented quadratic increase until the level of 75\% CPM in the ration. The concentration of the ammonia nitrogen and the $\mathrm{pH}$ of ruminal liquid did not differ in function of the substitution levels of the COR to CPM. It was concluded that CPM can totally substitute COR in the sheep ration.
\end{abstract}

Key Words: cassava by-product flour, corn, digestibility, intake, nitrogen balance, sheep

\section{Introdução}

A alimentação dos animais representa um dos maiores custos na produção animal, principalmente quando se utilizam fontes alimentares como o milho, que apesar das elevadas qualidades nutricionais apresentam em geral um custo elevado. Alguns subprodutos de indústria, como aqueles da produção de farinha de mandioca (casca de mandioca, farinha de varredura) possuem potencial e disponibilidade para serem utilizados como alimento energético e podem ser usados na alimentação de ruminantes (Pereira, 1987).

A mandioca (Manihot esculenta, Crantz), uma fonte rica em energia para as rações animais, é um

${ }^{1}$ Prof. da Pós-Graduação em Zootecnia da Universidade Estadual de Maringá (UEM), Av. Colombo, 3690, CEP 87020-900, bolsista do CNPq. E.mail: Imzeoula@uem.br

2 Aluno da Pós-Graduação (Mestrado) - UEM, Av. Colombo, 3690, CEP 87020-900. E.mail: ljgeron@yahoo.com.br

3 Aluno da Pós-Graduação (Doutorado) - UEM, Av. Colombo, 3690, CEP 87020-900. E.mail: caldas@wnet.com.br

${ }_{5}^{4}$ Bolsista de Iniciação Cientifica do CNPq.

${ }^{5}$ Prof. CESUMAR - Centro Ensino Superior Maringá - Maringá - PR

${ }^{6}$ Mestre em Zootecnia, Prof CIES - Centro Integrado de Ensino Superior. Campo Mourão - PR 
alimento que contém 3,04 Mcal de energia metabolizável (EM)/kg de matéria seca (MS), sendo portanto, próxima à EM do milho, com 3,25 Mcal/kg de MS (NRC, 1996).

A farinha de varredura é obtida durante a limpeza de todo o material perdido no chão, formado por farinha, pó e fibra, e apresenta elevados teores de amido $(80,0 \%)$ e de matéria seca $(90,0 \%)$. Sua composição química é muito semelhante à farinha de mandioca (Caldas Neto et al., 2001b).

$\mathrm{O}$ fornecimento de farinha de varredura e raspa de mandioca em rações para novilhas mestiças confinadas e bezerros holandeses, em substituição total ao milho, levou a redução no consumo de matéria seca (Marques, 1999; Jorge et al. 2002a).

Maior fermentação ruminal e o maior aproveitamento no trato digestivo total têm sido verificados, quando os animais são alimentados com rações que contenham como fonte energética a mandioca em comparação ao milho (Caldas Neto, 1999; Marques, 1999; Jorge et al., 2002b).

Os microrganismos do rúmen degradam as fontes protéicas, produzindo o nitrogênio amoniacal $\left(\mathrm{N}-\mathrm{NH}_{3}\right)$, que é utilizado para incorporação e crescimento. $\mathrm{O}$ crescimento da flora e fauna ruminal, por sua vez, tem o papel fundamental na degradação da fibra, sendo maior à medida que ocorre maior concentração de microrganismos no rúmen. De acordo com Smith et al. (1972), no rúmen a atividade máxima de organismos celulolíticos ocorreria em um $\mathrm{pH}$ variando de 6,0 e 6,8 .

O estudo do balanço energético possibilita avaliar o teor energético de alimentos, as exigências de energia dos animais e as eficiências de utilização da energia metabolizável para mantença e ganho de peso. A eficiência de utilização de EM para produção é influenciada, principalmente, pelas características da dieta, pelo valor comparativo de volumosos e concentrados, o teor de fibra, o tempo de ingestão e ruminação e as relações de ácidos graxos voláteis no rúmen (Van Soest, 1994).

O objetivo deste trabalho foi avaliar os efeitos da substituição do milho pela farinha de varredura da mandioca sobre consumo voluntário, digestibilidade total, balanço de nitrogênio, valor energético e determinar a concentração de nitrogênio amoniacal $\left(\mathrm{N}-\mathrm{NH}_{3}\right)$ e o $\mathrm{pH}$ no líquido ruminal dos ovinos submetidos às rações experimentais.

\section{Material e Métodos}

O experimento foi conduzido na Fazenda Experimental de Iguatemi (FEI), no setor de Digestibilidade de Ruminantes e as análises foram realizadas no Laboratório de Análises de Alimentos e Nutrição do Departamento de Zootecnia (DZO) da Universidade Estadual de Maringá (UEM).

Foram utilizados quatro ovinos, machos, castrados com peso médio de $41,4 \mathrm{~kg}$ em um ensaio de digestibilidade, adotando o método de coleta total de fezes. Os animais foram colocados em gaiolas metabólicas com dispositivo para coleta de urina e em cada animal foi adaptado uma sacola de napa, para coleta das fezes. Cada gaiola continha um comedouro e um bebedouro metálico individual de aço galvanizado.

As rações isoprotéicas e isoenergéticas foram balanceadas para apresentar 11,0\% de PB e 2,0 Mcal de energia metabolizável (EM) $/ \mathrm{kg}$ de acordo com o NRC (1975). Eram compostas de farelo de soja (FS), milho integral triturado (MI), farinha de varredura (FV), feno de Tífton 85 (Cynodon dactylum) de 42 dias, e sal mineral. A relação volumoso:concentrado foi de 50:50. A composição química-bromatológica do feno e dos alimentos utilizados na formulação da ração pode ser observada na Tabela 1 .

O fornecimento das rações para os animais foi estipulado de forma a permitir $10 \%$ de sobra e $10 \mathrm{~g}$ de sal mineral eram adicionadas às rações diariamente.

As rações foram diferenciadas conforme os níveis de substituição do milho pela farinha de varredura $(25,50,75$ e $100 \%)$ e estão apresentadas na Tabela 2. Cada período experimental (total de quatro períodos) teve uma adaptação de 15 dias e os animais recebiam as rações experimentais à vontade. As rações foram fornecidas duas vezes ao dia, sendo divididas em duas porções iguais, uma pela manhã (8h) e outra à tarde (16h).

Os períodos de coleta tiveram duração de 7 dias, nos quais eram coletadas amostras de fezes, urina, alimento fornecido e sobras. No último dia de cada período de coleta, era realizada a coleta de líquido ruminal, através de sonda esofágica.

As fezes eram pesadas diariamente pela manhã, homogeneizadas e $10 \%$ do total destas fezes eram acondicionadas em sacos plásticos. Para cada animal foi destinado um saco plástico por dia devidamente identificado. 
Tabela 1 - Composição química dos alimentos (\%MS) ${ }^{1}$

Table 1 - Chemical composition of the feed (\%DM)

\begin{tabular}{|c|c|c|c|c|c|c|}
\hline $\begin{array}{l}\text { Alimentos } \\
\text { Feeds }\end{array}$ & $\begin{array}{l}M S \\
D M\end{array}$ & $\begin{array}{l}\text { MO } \\
\text { OM }\end{array}$ & $\begin{array}{l}\mathrm{PB} \\
C P\end{array}$ & $\begin{array}{l}\mathrm{FDN} \\
N D F\end{array}$ & $\begin{array}{l}\text { Amido } \\
\text { Starch }\end{array}$ & $\begin{array}{l}\text { Cinzas } \\
\text { Ashes }\end{array}$ \\
\hline $\begin{array}{l}\text { Farelo de soja } \\
\text { Soybean meal }\end{array}$ & 89,98 & 93,54 & 49,75 & 15,13 & 3,73 & 6,46 \\
\hline $\begin{array}{l}\text { Milho } \\
\text { Corn }\end{array}$ & 87,56 & 98,96 & 8,84 & 12,33 & 73,74 & 1,04 \\
\hline $\begin{array}{l}\text { Farinha de varredura } \\
\text { Cassava by-product meal }\end{array}$ & 90,09 & 98,84 & 2,05 & 12,31 & 86,06 & 1,15 \\
\hline $\begin{array}{l}\text { Feno de Tifton } 85 \\
\text { Cynodon dactylum hay }\end{array}$ & 91,48 & 93,05 & 7,55 & 80,46 & 1,19 & 6,95 \\
\hline
\end{tabular}

${ }^{1} \mathrm{MS}=$ matéria seca, $\mathrm{MO}=$ matéria orgânica, $\mathrm{PB}=$ proteína bruta, FDN = fibra em detergente neutro.

${ }^{1} D M=$ dry matter,$O M=$ organic matter,$C P=$ crude protein, $N D F=$ neutral detergent fiber.

Tabela 2 - Composição percentual e química das rações experimentais (\% na MS) ${ }^{1}$

Table 2 - Percentage and chemical composition of experimental diets (\% dry matter) ${ }^{1}$

\begin{tabular}{|c|c|c|c|c|}
\hline \multirow[t]{2}{*}{$\begin{array}{l}\text { Alimentos } \\
\text { Feeds }\end{array}$} & \multicolumn{4}{|c|}{$\begin{array}{c}\text { Níveis de substituição (\%) } \\
\text { Levels of substitution (\%) }\end{array}$} \\
\hline & $\mathrm{R} 25$ & R50 & $\mathrm{R} 75$ & $\mathrm{R} 100$ \\
\hline Milho & 30,4 & 20,3 & 10,2 & - \\
\hline \multicolumn{5}{|l|}{ Corn } \\
\hline Farinha de varredura & 8,0 & 18,0 & 29,1 & 37,7 \\
\hline $\begin{array}{l}\text { Cassava by-product meal } \\
\text { Farelo de soja }\end{array}$ & 6,6 & 8,7 & 10,7 & 12,3 \\
\hline $\begin{array}{l}\text { Soybean meal } \\
\text { Feno de Tifton } 85\end{array}$ & 55,0 & 53,0 & 50,0 & 50,0 \\
\hline & \multicolumn{4}{|c|}{$\begin{array}{l}\text { Composição química } \\
\text { Chemical composition }\end{array}$} \\
\hline Energia bruta (Mcal/kg) & 4,3 & 4,3 & 4,3 & 4,2 \\
\hline $\begin{array}{l}\text { Gross energy } \\
\text { Matéria seca }(\%)\end{array}$ & 91,2 & 91,2 & 91,1 & 91,2 \\
\hline \multicolumn{5}{|l|}{ Dry matter } \\
\hline $\begin{array}{l}\text { Matéria orgânica } \\
\text { Organic matter }\end{array}$ & 95,2 & 95,2 & 95,2 & 95,1 \\
\hline $\begin{array}{l}\text { Proteína bruta } \\
\text { Crude protein }\end{array}$ & 10,8 & 10,9 & 10,9 & 10,9 \\
\hline $\begin{array}{l}\text { Fibra em detergente neutro } \\
\text { Neutral detergent fiber }\end{array}$ & 50,5 & 49,1 & 47,1 & 47,2 \\
\hline $\begin{array}{l}\text { Amido } \\
\text { Starch }\end{array}$ & 32,2 & 31,4 & 33,6 & 33,5 \\
\hline $\begin{array}{l}\text { Cinzas } \\
\text { Ash }\end{array}$ & 4,8 & 4,8 & 4,8 & 4,9 \\
\hline
\end{tabular}

Para coleta de urina foram utilizados baldes plásticos cobertos com tela para evitar contaminação com pêlos, ração e fezes. Cada balde continha $20 \mathrm{~mL}$ de $\mathrm{HCl}$ (1:1) para evitar a volatilização de nitrogênio e possível fermentação. A coleta da urina era reali- zada sempre no mesmo horário da manhã. A urina total era medida diariamente e $5 \%$ do total era amostrado e acondicionado em um único frasco de vidro (amostra composta), para cada animal em cada período experimental.

\section{R. Bras. Zootec., v.32, n.2, p.491-502, 2003}


Após o término de cada período de coleta, era realizada a coleta de líquido ruminal de cada animal. Foram realizadas cinco coletas por animal, nos tempos: 0 (antes da alimentação), 2, 4, 6 e 8 horas (após a primeira alimentação). Foi utilizada uma bomba de vácuo com pressão de $40 \mathrm{~mm} \mathrm{Hg}$, e uma sonda de silicone com 2,0 metros de comprimento por $12 \mathrm{~mm}$ de diâmetro, que era lubrificada com óleo mineral (Nujol) antes de ser introduzida pela boca do animal. Foram retirados aproximadamente $100 \mathrm{~mL}$ de líquido do rúmen de cada animal para que ao ser filtrado com um tecido duplo de algodão sobrasse em torno de $80 \mathrm{~mL}$, que eram homogeneizados e com o potenciômetro era medido o $\mathrm{pH}$. Depois, aproximadamente $50 \mathrm{~mL}$ do líquido era transferido para um frasco devidamente etiquetado com $1 \mathrm{~mL}$ de $\mathrm{H}_{2} \mathrm{SO}_{4}$ para cessar a fermentação.

De cada alimento utilizado na formulação das rações e $10 \%$ do total das sobras foram amostrados para posterior análise. Logo após a coleta, todas as amostras coletadas eram guardadas em freezer à temperatura de $-10^{\circ} \mathrm{C}$ para posterior análise.

As amostras dos alimentos, das sobras e das fezes foram descongeladas para serem pré-secadas em estufa de ventilação forçada de ar com temperatura controlada $\left(50\right.$ a $\left.55^{\circ} \mathrm{C}\right)$. Após a pré-secagem, todo o material foi moído em moinhos com peneira de crivo de $1 \mathrm{~mm}$, e as amostras compostas foram acondicionados em vidros hermeticamente fechados e identificados.

Os teores de matéria seca (MS), matéria orgânica (MO), energia bruta (EB), proteína bruta (PB), fibra em detergente neutro (FDN) e nitrogênio presentes nas amostras foram determinados de acordo com Silva (1990). Os teores de amido foram determinados pelo método de Poore et al. (1989), adaptado por Pereira E Rossi (1995), para leitura da glicose com Kit Enzcolor. A dosagem de amônia das amostras de líquido ruminal foi realizada por destilação com KOH 2N, segundo técnica descrita por Ferner (1965), modificada por Vieira (1984).

Foram determinados os balanços de nitrogênio (BN) e de energia (BE) dos animais submetidos às rações experimentais. Os valores de energia digestível (ED) foram obtidos a partir da energia bruta ingerida descontados a das fezes. Os nutrientes digestíveis totais (NDT) foram estimados a partir da ED, usandose a seguinte fórmula de conversão descrita por Coelho da Silva \& Leão, (1979): NDT = (EDkcal/kg/4,409)x100.

Os valores de energia metabolizável (EM), energia liquida de mantença (Elm) e energia liquida de ganho (Elg) foram calculados conforme recomenda- ções de Sniffen et al. (1992): $\mathrm{EM}=0,82 \mathrm{ED}$

$\mathrm{Elm}=-1,12+1,37 \mathrm{EM}-0,138 \mathrm{EM}^{2}+0,0105 \mathrm{EM}^{3}$

$\mathrm{Elg}=-1,65+1,42 \mathrm{EM}-0,174 \mathrm{EM}^{2}+0,0122 \mathrm{ME}^{3}$

A EM também foi determinada por meio do balanço de energia: $\mathrm{EM}=(\mathrm{Ebi}-\mathrm{Ebf}-\mathrm{Ebu}-\mathrm{Ebg})$; onde: Ebi = energia bruta ingerida; Ebf = energia bruta das fezes; Ebu = energia bruta da urina e Ebg = energia perdida nos gases, sendo considerado 5\% da EB ingerida (Coelho da Silva \& Leão, 1979).

O delineamento experimental utilizado foi o quadrado latino $4 \times 4$, com quatro tratamentos e quatro repetições. As análises estatísticas das variáveis estudadas foram interpretadas por análises de variância e regressão, utilizando o Sistema de Análises Estatísticas e Genéticas (SAEG), utilizando o seguinte modelo:

$$
\mathrm{Y}_{i j k}=\mathrm{m}+\mathrm{N}_{i}+\mathrm{Pj}+\mathrm{A}_{i j k}+\mathrm{e}_{i j k}
$$

em que: $\mathrm{Y}_{i j k}=$ coeficientes de digestibilidade da variável estudada no indivíduo $k$, do período $j$, recebendo a ração com nível $i$ de substituição do milho pelo farinha de varredura de mandioca; $\mathrm{m}=$ constante geral da variável; $\mathrm{N}_{i}=$ efeito do nível $i$ de substituição do milho por farinha de varredura de mandioca $(i=25$, 50, 75 e 100); $\mathrm{Pj}=$ efeito do período $j, \mathrm{~A}_{i j k}=\operatorname{animal} k$, no período $j$, recebendo a ração com nível $i$ de substituição do milho pela farinha de varredura e $\mathrm{e}_{i j k}=$ erro aleatório associado à cada observação $\mathrm{Y}_{i j k}$.

Os graus de liberdade para níveis de substituição do milho pela farinha de varredura de mandioca foram desdobradas em polinômios ortogonais.

Foi utilizada a análise de regressão para as concentrações de $\mathrm{pH}$ e $\mathrm{N}-\mathrm{NH}_{3}$ do líquido ruminal em função do tempo após a alimentação da manhã $(0,2$, 4, 6 e 8 horas) para cada tratamento.

\section{Resultados e Discussão}

Os dados de consumo médio diário de matéria seca (MS), matéria orgânica (MO), fibra em detergente neutro (FDN) e amido (AM), em função do peso vivo (\% PV) e peso metabólico $\left(\mathrm{g} / \mathrm{kg}{ }^{0,75}\right)$, são apresentados na Tabela 3.

Os consumos de MS, MO, FDN, expressos como $\%$ de peso vivo e peso metabólico, não foram influenciados $(\mathrm{P}>0,05)$ com o aumento dos níveis de farinha de varredura (FV) em substituição ao milho em até $100 \%$. Estes resultados diferem daqueles observados na literatura que relatam reduções no consumo de MS de bezerros, ovelhas, novilhas confinadas e bovinos mestiços confinados, quando a mandioca na forma de 
Tabela 3 - Consumo médio diário de matéria seca (MS), matéria orgânica (MO), fibra em detergente neutro (FDN) e amido (AM) das rações experimentais ${ }^{1}$

Table 3 - $\quad$ Average daily intake ( $\mathrm{kg} /$ day) of dry matter (DM), organic matter (OM), neutral detergent fiber (NDF) and starch of experimental diets

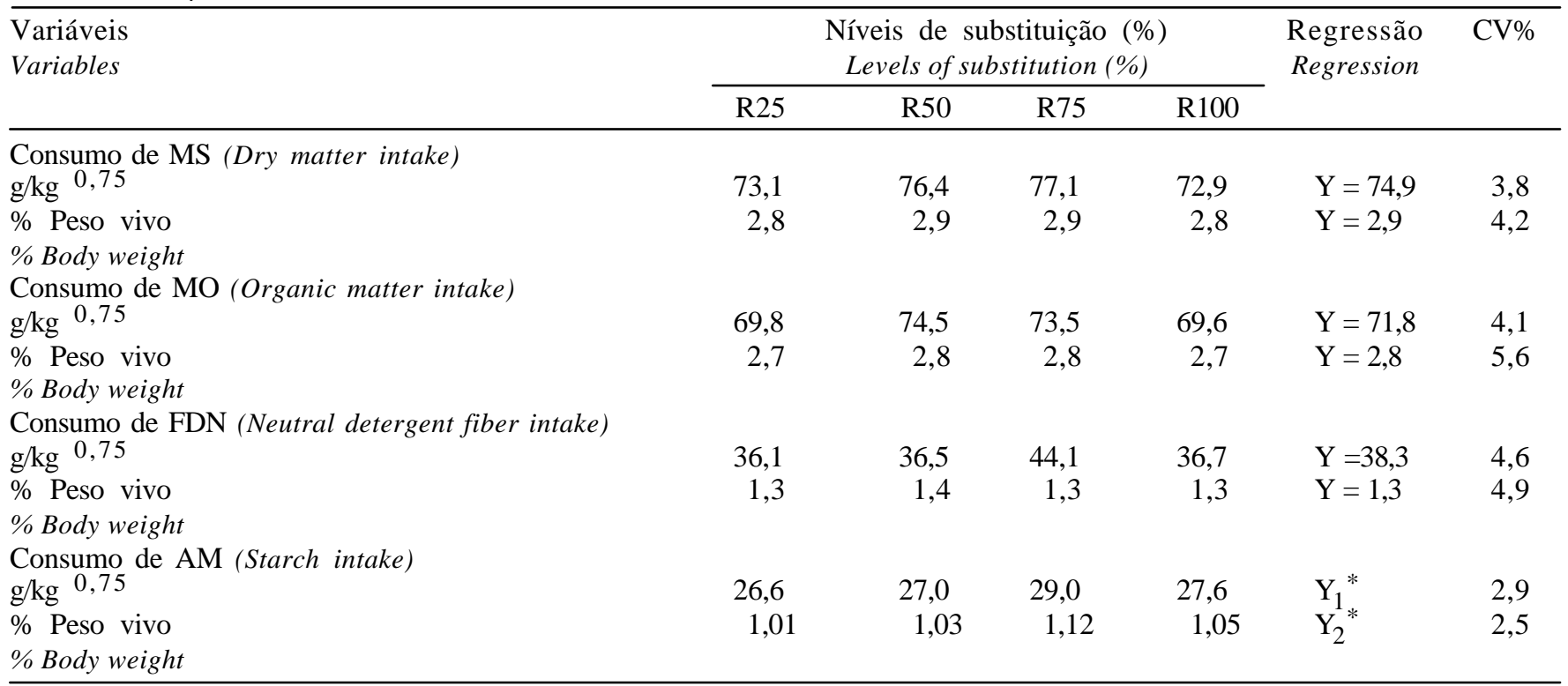

${ }^{1}$ R25, R50, R75 e R100: respectivamente, rações com farinha de varredura em substituição ao milho nos níveis de $25,50,75$ e $100 \%$. $Y_{1_{*}^{*}=28,10823+0,01971743 X-0,0007278391 X^{2}}^{*} R^{2}=0,61$

$\mathrm{Y}_{2}^{1 *}=1,1559966-0,09825628 \mathrm{X}-0,0420834 \mathrm{X}^{2} \quad \mathrm{R}^{2}=0,52$

${ }^{1} R 25, R 50, R 75$ and R100: respectively, levels of substitution (25, 50, 75 and $\left.100 \%\right)$ cassava by-product meal to corn in the experimental diets.

raspa, ou farinha ou ainda farinha de varredura de mandioca, substituíram o milho em níveis acima de 50\% (Fichtner et al., 1990; Zinn \& DePetrs, 1991; Peixoto \& Warner, 1993; Stumpf \& López, 1994; Marques, 1999; Jorge et al., 2002a). A redução no consumo da farinha de varredura de mandioca foi atribuída, pelos diversos autores, quanto aos seus aspectos físico-químicos: sua pulverulência (textura de pó), apresentar baixa palatabilidade, ser seca (somente $0,6 \%$ de extrato etéreo) e que os animais não mastigam a farinha como fariam com o milho moído grosseiramente. Uma mastigação mais prolongada conduz a uma maior secreção salivar com alto teor de mucina e enzimas, que facilitam a formação do bolo adesivo do alimento e a deglutição (Hill,1970, citado por Peixoto \& Warner, 1993). Todavia, no caso de alimentos secos, a composição da saliva se altera tornado-se mais aquosa com pouca mucina. Marques (1999) verificou que as novilhas que consumiam rações que continham farinha de varredura de mandioca, em substituição total ao milho, ao entrar em contato com a saliva formava uma massa pastosa na boca dos animais, fazendo com que estes ficassem com a língua para fora durante um tempo maior, dificultando a ingestão.
Estes fatores citados provavelmente podem explicar o menor consumo de MS quando a FV substitui totalmente o milho para bezerros e novilhos. Também reduções no consumo de MS foram observadas para vacas leiteiras quando fontes de amido de rápida degradação ruminal foram fornecidas (Sauvant et al., 1994; Overton et al., 1995; Santos et al., 1997), no entanto, fontes de amido de menor degradação levam a uma fermentação ruminal relativamente mais equilibrada não alterando a ingestão de MS (Nocek \& Tamminga, 1991; Sauvant et al., 1994).

A fermentação do amido causa um aumento na produção e absorção de ácidos graxos voláteis (AGV), associado com aumentos na concentração de AGV ruminal (Reynolds et al., 1997). O acúmulo de ácidos no rúmen pode causar danos no epitélio do rúmen e inibir a atividade de microrganismos celulolíticos (Ørskov et al., 1986), refletindo em reduções na ingestão de forragem e na ingestão total de MS (Grant, 1994) pela redução na digestibilidade da fibra. No entanto, no presente trabalho o fornecimento de $100 \%$ de FV (fonte de amido de alta degradabilidade ruminal) não influenciou o consumo de MS que foi em média de $72,9 \mathrm{gMS} / \mathrm{kg}^{0,75}$ ou 2,8\% PV, a digestibilidade da FDN $(53,9 \%)$ e o $\mathrm{pH}$ ruminal ficou acima de 6,2 
quando fornecida a ovinos (Tabelas 6 e 8 , respectivamente). Ainda, a forma de apreensão do alimento diferente entre as espécies resultou em consumo semelhante entre as rações fornecidas aos ovinos.

$\mathrm{O}$ consumo de amido apresentou um efeito quadrático crescente $(\mathrm{P}<0,05)$ até o nível de $75 \%$ de $\mathrm{FV}$, porém foi diminuindo com $100 \%$ de FV. Este resultado pode ser um reflexo do consumo de MS, que apesar de não ter sido observado efeito significativo, numericamente aumentou até o nível de $75 \%$ de FV e diminuiu para ração com $100 \%$ de FV.

Os consumos médios diários de nitrogênio $(\mathrm{N}), \mathrm{N}$ excretado nas fezes e urina e balanço de $\mathrm{N}(\mathrm{BN})$ encontram-se na Tabela 4 . $\mathrm{O}$ consumo de $\mathrm{N}$ pelos animais não foi influenciado pelos níveis de substituição do MI pela FV, observando-se valor médio de $24,4 \mathrm{~g} /$ dia e $1,4 \mathrm{~g} / \mathrm{kg}^{0,75}$. Vale ressaltar que as rações eram isoprotéicas e a fonte de proteína utilizada foi o farelo de soja.

Aumento nos teores de PB da ração, no consumo de $\mathrm{N}$ e no tipo de fonte de nitrogênio utilizado pode refletir na relação entre o $\mathrm{N}$ excretado pelas vias urinária e fecal, como mostra a literatura. No presente trabalho, as perdas de nitrogênio foram próximas entre as vias urinária e fecal, respectivamente, de 31,0 e $34,3 \%$ do nitrogênio consumido (NC), provavelmente devido às rações apresentarem o farelo de soja e o feno de tifton como as únicas fontes de proteína e conter $10,9 \%$ de PB na MS.

Diminuição na proporção de compostos nitrogenados fecais à medida que a ingestão de $\mathrm{N}$ aumenta, foi observada por Stallcup et al. (1975), citados por Valadares et al. (1997). Lavezzo et al. (1996), trabalhando com ovinos, recebendo dietas isoprotéicas $(15,4 \%$ de PB na MS) com fontes de N orgânico (farelo de soja) e inorgânico (uréia), observou maior excreção de $\mathrm{N}$ via urina (52,3\% do NC) que nas fezes (24,4\% do NC). Provavelmente, o excesso de amônia resultante da rápida hidrólise ruminal da uréia e sua posterior absorção pelas paredes ruminais, aumentou a excreção de $\mathrm{N}$ pela urina, na forma de uréia. Também, Bett et al. (1999) observaram maior excreção de $\mathrm{N}$ urinário em relação ao $\mathrm{N}$ fecal, utilizando farelo de soja $(58,4$ e $22,2 \%$ do NC) e farelo de canola (53,3 e $28,2 \%$ do NC), respectivamente, como fonte protéica, em cordeiros recebendo rações em média com $16,6 \%$ de PB na MS. Tibo et al. (2000) verificaram maior excreção de $\mathrm{N}$ urinário em relação ao $\mathrm{N}$ fecal, variando de forma decrescente linear $(\mathrm{P}<0,05)$ de 51,6 a 43,9\% do $\mathrm{NC}$, de acordo com os níveis crescente de concentrado na dieta, fato explicado pela maior retenção de $\mathrm{N}$ pelo animal.

Tabela 4 - Média e regressão dos consumos de nitrogênio $(N), N$ excretado nas fezes e urina e balanço de nitrogênio expresso em $\mathrm{g} / \mathrm{dia}, \mathrm{g} / \mathrm{kg}^{0,75}$ em relação ao nitrogênio consumido (\%NC)

Table 4 - Average and regression of intake nitrogen $(N), N$ excreted in feces and urine and nitrogen balance in $\mathrm{g} / \mathrm{day}, \mathrm{g} / \mathrm{kg}^{0,75}$ in relation of intake $N(\% I N)$

\begin{tabular}{|c|c|c|c|c|c|c|}
\hline \multirow[t]{2}{*}{$\begin{array}{l}\text { Variáveis } \\
\text { Variables }\end{array}$} & \multicolumn{4}{|c|}{$\begin{array}{l}\text { Níveis de substituição (\%) } \\
\text { Levels of substitution (\%) }\end{array}$} & \multirow[t]{2}{*}{$\begin{array}{l}\text { Regressão } \\
\text { Regression }\end{array}$} & \multirow[t]{2}{*}{$\mathrm{CV} \%$} \\
\hline & R25 & R50 & R75 & R100 & & \\
\hline \multicolumn{7}{|c|}{$\mathrm{N}$ consumido (Intake of $N$ ) } \\
\hline g/dia & 24,1 & 25,3 & 24,5 & 23,6 & $\mathrm{Y}=24,4$ & 5,4 \\
\hline $\mathrm{g} / \mathrm{kg} \quad 0,75$ & 1,3 & 1,4 & 1,4 & 1,3 & $Y=1,4$ & 3,7 \\
\hline \multicolumn{7}{|c|}{$\mathrm{N}$ fecal ( $N$ feces $)$} \\
\hline g/dia & 8,2 & 8,6 & 8,4 & 8,3 & $\mathrm{Y}=8,4$ & 6,2 \\
\hline $\mathrm{g} / \mathrm{kg} \quad 0,75$ & 0,5 & 0,5 & 0,5 & 0,5 & $Y=0,5$ & 5,2 \\
\hline$\% \mathrm{NC}$ & 34,0 & 34,0 & 33,9 & 35,2 & $Y=34,3$ & 7,7 \\
\hline \multicolumn{7}{|c|}{$\mathrm{N}$ urina ( $N$ urine) } \\
\hline g/dia & 7,3 & 7,4 & 7,9 & 7,5 & $Y=7,5$ & 21,6 \\
\hline $\mathrm{g} / \mathrm{kg} \quad 0,75$ & 0,4 & 0,4 & 0,5 & 0,4 & $\mathrm{Y}=0,4$ & 22,3 \\
\hline$\% \mathrm{NC}$ & 30,3 & 29,3 & 32,2 & 31,8 & $\mathrm{Y}=30,9$ & 19,9 \\
\hline \multicolumn{7}{|c|}{ Balanço de nitrogênio (Nitrogen balance) } \\
\hline g/dia & 8,6 & 9,3 & 8,3 & 7,9 & $Y=8,5$ & 18,1 \\
\hline $\mathrm{g} / \mathrm{kg} \quad 0,75$ & 0,4 & 0,5 & 0,5 & 0,4 & $\mathrm{Y}=0,5$ & 16,7 \\
\hline$\% \mathrm{NC}$ & 35,5 & 36,7 & 33,3 & 32,3 & $\mathrm{Y}=34,7$ & 16,8 \\
\hline
\end{tabular}

R25, R50, R75 e R100: respectivamente, níveis de farinha de varredura em substituição ao milho; N nitrogênio. R25, R50, R75 and R100: respectively, levels of substitution (25, 50, 75 and 100\%) cassava by-product meal to corn; N nitrogen. 
O balanço de nitrogênio $(\mathrm{BN})$ não diferiu entre os níveis de substituição do MI pela FV (Tabela 4), sendo o valor médio do $\mathrm{BN}$ de $8,5 \mathrm{~g} / \mathrm{dia}$ e em relação ao $\mathrm{N}$ consumido (NC) de $34,7 \%$. Este valor de retenção de $\mathrm{N}$ é superior ao observado para ovinos (22,1\% do NC) alimentados com rações com 17,5\% de $\mathrm{PB}$ e sincronizadas para fontes de amido e nitrogênio, de alta ou baixa degradabilidade ruminal (Zeoula et al., 1999b). De acordo com Tibo et al. (2000), o BN aumentou linearmente com os níveis de concentrados da dieta variando de 6,4 a $53,3 \mathrm{~g} / \mathrm{dia}$ e 0,1 a $0,7 \mathrm{~g} / \mathrm{kg}^{0,75}$. Foi demonstrado que o maior aporte de compostos de $\mathrm{N}$ no abomaso resultou em maior retenção de $\mathrm{N}$ no organismo animal.

Os consumos de energia bruta (CoEB), energia digestível (CoED), energia metabolizável (CoEM), energia líquida de mantença $(\mathrm{CoElm})$ e energia líquida de ganho (CoElg), e os valores energéticos das rações experimentais estão descritos na Tabela 5. Os consumos de ED, EM, ELm e ELg, expressos em função do peso metabólico dos animais, não foram influenciados pelos níveis de substituição. Estes resultados estão de acordo com os observados por Jorge et al. (2002b), que também não observaram diferença, para o consumo de EM, Elm e Elg, substituindo o MI pela FV, em rações de bezerros.

Houve efeito quadrático para o consumo de EB $\mathrm{kcal} / \mathrm{kg}^{0,75}$, em função do nível de substituição do MI pela $\mathrm{FV}$, com valores estimados, variando de 301,7 $\mathrm{kcal} / \mathrm{kg}{ }^{0,75}$ (para a ração com $100 \%$ de FV em substituição ao MI) a $326,9 \mathrm{kcal} / \mathrm{kg}^{0,75}$ (para a ração com $75 \%$ de FV em substituição ao MI).

Os teores dos nutrientes digestíveis totais (NDT) e a energia digestível (ED) não diferiram com os níveis de substituição do MI pela FV, com valores médios de $65,7 \%$ e $2,9 \mathrm{Mcal} / \mathrm{kg}$. O valor médio da energia metabolizável $\left(\mathrm{EM}_{1}\right)$ obtida através da equação de Sniffen (1993) foi 2,4 Mcal de EM/kg e o mesmo valor foi observado para $\mathrm{EM}_{2}$, obtida por meio do balanço de energia, considerando a perda de metano como 5\% da EB ingerida, conforme Coelho da Silva \& Leão (1979). A energia líquida de mantença (Elm) e de ganho (Elg) das rações experimentais não diferiram, com valores médios de 1,6 e 1,1 Mcal/kg, respectivamente.

Os coeficientes de digestibilidade aparente (CDA) da matéria seca (MS), matéria orgânica (MO), proteína bruta $(\mathrm{PB})$, fibra em detergente neutro (FDN), energia bruta (EB) e amido (AM) podem ser observados na Tabela 6 . Não houve efeito $(\mathrm{P}>0,05)$

Tabela 5 - Consumos de energia bruta (CoEB), energia digestível (CoED), energia metabolizável (CoEM), energia líquida de mantença (CoElm) e de energia líquida de ganho (CoElg), e valores energéticos das rações experimentais

Table 5 - Intake of gross energy (IGE), digestible energy (IDE), metabolizable energy (IME), net energy for mantence (INEM), net energy for body gain (INEG), and energy values of experimental diets

\begin{tabular}{|c|c|c|c|c|c|c|}
\hline \multirow[t]{2}{*}{$\begin{array}{l}\text { Variáveis } \\
\text { Variables }\end{array}$} & \multicolumn{4}{|c|}{$\begin{array}{l}\text { Níveis de substituição (\%) } \\
\text { Levels of substitution (\%) }\end{array}$} & \multirow[t]{2}{*}{$\begin{array}{l}\text { Regressão } \\
\text { Regression }\end{array}$} & \multirow[t]{2}{*}{$\mathrm{CV} \%$} \\
\hline & $\mathrm{R} 25$ & R50 & R75 & $\mathrm{R} 100$ & & \\
\hline CoEB (IGE) kcal $/ \mathrm{kg}^{0,75}$ & 315,5 & 325,9 & 326,9 & 301,7 & 1 & 3,3 \\
\hline $\mathrm{CoED}(I D E) \mathrm{kcal} / \mathrm{kg}^{0,75}$ & 215,8 & 222,5 & 225,3 & 201,1 & $Y=216,2$ & 5,7 \\
\hline CoEM (IME) kcal $/ \mathrm{kg}^{0,75}$ & 176,9 & 183,0 & 184,8 & 164,9 & $Y=177,4$ & 5,8 \\
\hline CoELm (INEM) $\mathrm{kcal} / \mathrm{kg}^{0,75}$ & 121,2 & 125,6 & 126,9 & 111,3 & $Y=121,2$ & 6,9 \\
\hline CoELg (INEG) $\mathrm{kcal} / \mathrm{kg}^{0}, 75$ & 78,0 & 79,3 & 80,4 & 75,8 & $Y=78,4$ & 8,2 \\
\hline $\operatorname{NDT}(T D N) \%$ & 67,0 & 66,0 & 66,0 & 63,7 & $Y=65,7$ & 4,2 \\
\hline $\mathrm{ED}(D E) \mathrm{Mcal} / \mathrm{kg}$ & 3,0 & 2,9 & 2,9 & 2,8 & $\mathrm{Y}=2,9$ & 3,1 \\
\hline $\mathrm{EM}_{1}\left(M E_{1}\right) \mathrm{Mcal} / \mathrm{kg}$ & 2,4 & 2,4 & 2,4 & 2,3 & $Y=2,4$ & 3,0 \\
\hline $\mathrm{EM}_{2}\left(M E_{2}\right) \mathrm{Mcal} / \mathrm{kg}$ & 2,5 & 2,4 & 2,4 & 2,3 & $Y=2,4$ & 6,0 \\
\hline $\mathrm{Elm}(N E M) \mathrm{Mcal} / \mathrm{kg}$ & 1,7 & 1,6 & 1,6 & 1,5 & $Y=1,6$ & 3,1 \\
\hline $\mathrm{Elg}(N E G) \mathrm{Mcal} / \mathrm{kg}$ & 1,1 & 1,0 & 1,0 & 1,1 & $Y=1,1$ & 3,0 \\
\hline
\end{tabular}

1. $Y=328,628-0,1613601(x)-0,014228(x)^{2}$

$r^{2}=0,97$

R25, R50, R75 e R100: respectivamente, níveis de farinha de varredura em substituição ao milho. EM 1 Mcal de EM/kg obtida pela equação de Sniffen; $\mathrm{EM}_{2}$ Mcal de EM/kg: $(\mathrm{Ebc}-\mathrm{Ef}-\mathrm{Eu}-\mathrm{Eg})$, em que: Ebc = energia bruta consumida; Ef = energia das fezes; Eu = energia da urina; $\mathrm{Eg}=$ energia dos gases considerando $5 \%$ de perdas.

R25, R50, R75 and R100: respectively, levels of substitution cassava by-product meal to corn. ME 1 Mcal ME/kg obtained by Sniffen equation; ME 2 Mcal $\mathrm{ME} / \mathrm{kg}$ (IGE - FE - UE - GE), where: IGE = intake gross energy, FE = feces energy, UE = urine energy, GE = gases energy with lost of $5 \%$ 
do nível de substituição do milho pela farinha de varredura sobre os coeficientes de digestibilidade aparente da MS, MO, PB, FDN e AM, com médias de digestibilidade de 69,$5 ; 71,2 ; 65,8 ; 53,9$ e 99,3\%, respectivamente.

No presente trabalho não foi observado efeito sobre a digestibilidade no trato total quando a farinha de varredura foi incluída no concentrado em substituição ao milho. No entanto, a literatura mostra que o fornecimento da mandioca reflete em maiores valores de digestão ruminal, degradabilidade ruminal e digestibilidade no trato gastrintestinal em relação aos grãos de cereais, especialmente o milho.

Marques (1999), trabalhando com novilhas mestiças, observou maior digestibilidade total da MS e do amido de rações compostas com raspa de mandioca, casca de mandioca e farinha de varredura em relação à ração composta com milho, em animais recebendo rações à vontade. Também Caldas Neto et al. (2001b), em estudo de digestão parcial e total, observaram que os concentrados que continham milho (MI), milho + casca de mandioca (MC), raspa de mandioca (RM) e farinha de varredura de mandioca (FV) como fonte energética, apresentaram maior digestão ruminal do AM, para as rações com raspa de mandioca e farinha de varredura e menor para as rações com milho. Estes resultados concordaram com os valores de degradabilidade ruminal do AM da mandioca de 79,1\% em relação ao milho de $57,8 \%$ obtidos por Zeoula et al. (1999a). Jorge et al. (2002b) observaram efeito linear crescente para os coeficientes de digestibilidade da matéria seca, proteína bruta e amido com o aumento no nível de inclusão de farinha de varredura em substituição ao milho em rações fornecidas para bezerros Holandeses.

A digestibilidade do amido é inversamente proporcional à quantidade de amilose (Van Soest, 1994). Assim a proporção desses polímeros lineares (amilose) e ramificados (amilopectina) presentes nos grãos de cereais, raízes e tubérculos, influenciam na taxa de degradação e na digestibilidade das diferentes fontes de amido. Também as matrizes de proteína e os corpos protéicos presentes no endosperma dos grãos afetam a utilização de amido pelos animais (Rooney \& Pflugfelder, 1986), indicando a importância da digestibilidade da proteína no valor nutricional dessas fontes energéticas. $\mathrm{O}$ amido da mandioca apresenta cerca de $83 \%$ de amilopectina e o milho $76 \%$ (Vilela \& Ferreira, 1987) e a ausência de matriz protéica na mandioca pode ser responsável pela maior digestibilidade do amido obtida para esta fonte energética em relação ao milho (Zeoula, 1990).

Para o coeficiente de digestibilidade aparente da energia bruta (CDA da EB) não houve efeito para as rações experimentais, com valor médio estimado de $68,0 \%$. Entretanto, Jorge et al. (2002b) observaram efeito linear crescente no CDA da EB em bezerros, à medida em que se elevaram os níveis de substituição do MI pela FV, com valores estimados, variando de 69,5 (para a ração com $0 \%$ de FV em substituição ao MI) a $76,5 \%$ (para a ração com $100 \%$ de FV em substituição ao MI).

Caldas Neto et al. (2001b) forneceram a novilhos sob consumo restrito diferentes fonte energéticas,

Tabela 6 - Média e regressão dos coeficientes de digestibilidade total da matéria seca (MS), matéria orgânica (MO), proteína bruta (PB), fibra em detergente neutro (FDN), energia bruta (EB) e amido (AM) e coeficientes de variação $(\mathrm{CV})$

Table 6 - Average and regression of total digestibility coefficient of dry matter (DM), organic matter (OM), crude protein (CP), neutral detergent fiber (NDF), gross energy (GE) and starch and coefficient of variation (CV)

\begin{tabular}{lccccc}
\hline \multirow{2}{*}{$\begin{array}{l}\text { Variáveis } \\
\text { Variables }\end{array}$} & \multicolumn{3}{c}{$\begin{array}{c}\text { Níveis de substituição (\%) } \\
\text { Levels of substitution (\%) }\end{array}$} & $\begin{array}{c}\text { Média } \\
\text { Mean }\end{array}$ \\
\cline { 2 - 5 } & $\mathrm{R} 25$ & $\mathrm{R} 50$ & $\mathrm{R} 75$ & $\mathrm{R} 100$ & 2,4 \\
MS (DM) & 69,7 & 69,3 & 70,4 & 68,5 & 69,5 \\
MO (OM) & 71,5 & 71,5 & 71,7 & 70,1 & 71,2 \\
PB (CP) & 66,0 & 66,1 & 65,9 & 65,2 & 65,8 \\
FDN (NDF) & 55,0 & 54,9 & 55,7 & 49,9 & 53,9 \\
EB (GE) & 68,5 & 68,3 & 68,7 & 66,6 & 6,3 \\
AM (Starch) & 98,9 & 99,3 & 99,3 & 99,5 & 3,0 \\
\hline
\end{tabular}

R25, R50, R75 e R100: respectivamente, níveis de farinha de varredura em substituição ao milho nas rações experimentais. R25, R50, R75 and R100: respectively, levels of substitution cassava by-product meal to corn in experimental diets. 
casca de mandioca, raspa de mandioca e farinha de varredura em substituição total ao milho, não encontraram diferença para o CDA da EB entre as rações contento $\mathrm{FV}(66,7 \%)$ e aquelas que continham MI (68,0\%). Prado et al. (1999), utilizando rações semelhantes àquelas utilizadas por Caldas Neto et al. (2001b), e sem restrição de consumo em novilhas mestiças confinadas, encontraram valores de CDA da EB maior para rações contendo FV $(62,6 \%)$ do que para as que continham MI $(56,6 \%)$.

As concentrações de nitrogênio amoniacal do líquido ruminal das rações experimentais em função da substituição do MI pela FV, nos tempos 0 horas antes da alimentação, 2, 4, 6 e 8 horas após à alimentação, podem ser observadas na Figura 1.

A concentração de nitrogênio amoniacal $\left(\mathrm{N}-\mathrm{NH}_{3}\right)$ do líquido de rúmen não diferiu em função dos níveis de substituição do MI pela FV, contudo houve efeito com relação ao tempo. As concentrações de $\mathrm{N}-\mathrm{NH}_{3}$ do líquido ruminal se comportaram de forma quadrática em função do tempo após a primeira alimentação, para todas as rações experimentais. A equação de regressão para a concentração $\mathrm{N}-\mathrm{NH}_{3}$, em função do tempo (T), foi a seguinte: $\mathrm{N}-\mathrm{NH}_{3}=10,9209$ $1,8660 \mathrm{~T}+0,1826 \mathrm{~T}^{2}$. A maior concentração estimada de $\mathrm{N}-\mathrm{NH}_{3}$ foi de $10,9 \mathrm{mg} / 100 \mathrm{~mL}$ de líquido ruminal no tempo 0 horas antes da alimentação, e a concentração mínimas foi de $6,2 \mathrm{mg} / 100 \mathrm{~mL}$ de líquido ruminal às 5,1 horas após a alimentação

Verifica-se que estes resultados mostraram comportamento inverso ao padrão observado na literatura, que é quadrático, porém com as concentrações

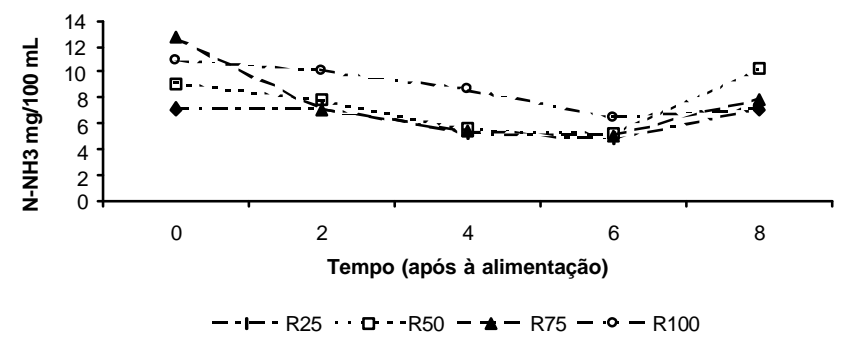

Figura 1 - Concentração do nitrogênio amoniacal $\left(\mathrm{N}-\mathrm{NH}_{3}\right)$ do líquido ruminal em função do tempo após à alimentação para as rações experimentais $(25,50,75$ e $100 \%$ de substituição do MI pela FV).

Figura 1 - $\mathrm{N}-\mathrm{NH}_{3}$ concentration of ruminal fluid in function of time after alimentation to experimental diets $(25$, 50, 75 and $100 \%$ substitution cassava by-product meal to corn). de máxima no tempo de 2 a 4 horas após a alimentação e de mínima no tempo zero hora antes da alimentação. Na Tabela 7, encontram-se os valores da concentração de nitrogênio amoniacal observados em função do tempo e as médias das rações experimentais.

As elevadas concentrações de $\mathrm{N}-\mathrm{NH}_{3}$ do líquido ruminal ocorridas antes das alimentações da manhã e da tarde (zero horae 8 horas) podem ter sido influenciada pela metodologia de coleta do líquido ruminal, obtida através da sonda esofágica. Foram coletados aproximadamente $100 \mathrm{~mL}$ de suco ruminal por coleta, e de acordo com Ortolani (1981), a quantidade de 300 $\mathrm{mL}$ de suco ruminal, não interferiu nos valores de $\mathrm{pH}$ quando foi utilizada a sonda esofágica na colheita de suco de rúmen de bovinos. Já coletas inferiores a 300 $\mathrm{mL}$ de suco ruminal exibiram distinta alcalinização e, portanto um $\mathrm{pH}$ anormal. Também foi observado, no presente trabalho, maior dificuldade na colheita do suco por meio da sonda esofágica nas primeiras horas após a ingestão do alimento.

Cameron et al. (1991) observaram aumentos nas concentrações de amônia ruminal antes do fornecimento das rações para bovinos e estes resultados também foram observados por Fregadolli et al. (2001) que concluíram que a secreção da saliva é estimulada antes mesmo da ingestão do alimento por estímulos sensoriais, como visualização do alimento e olfato. Portanto, o manejo e a movimentação na pesagem dos alimentos antes do fornecimento podem ter condicionado os animais, gerando ansiedade e estímulo para salivação, provocando aumento na concentração de amônia momentos antes da alimentação.

Verificou-se que os resultados obtidos para as concentrações de nitrogênio amoniacal do líquido de rúmen, mantiveram-se acima da concentração observada por Satter \& Roffler (1975) que foi de 5 $\mathrm{mg} / 100 \mathrm{~mL}$ de líquido ruminal, para que a mesma não limite o crescimento microbiano.

Os valores de $\mathrm{pH}$ do líquido ruminal observados não diferiram $(\mathrm{P}>0,05)$ para os diferentes níveis de substituição do MI pela FV (25, 50, 75 e 100\%), como mostra a Figura 2. Contudo, o pH do líquido ruminal diferiu $(\mathrm{P}<0,05)$ em relação ao tempo $(\mathrm{T})$, para todas as rações experimentais. Pela equação de regressão: $\mathrm{pH}=6,228464-0,0405 \mathrm{~T}+0,03350447 \mathrm{~T}^{2}$, foi estimado valor de pH máximo de 8,1 às 8,0 horas após à alimentação. Este resultado variou em relação aos observados (Tabela 8), que indica pH máximo de 7,0 
Tabela 7 - Concentração de nitrogênio amoniacal observado $\mathrm{mg} / 100 \mathrm{~mL}$ do líquido ruminal, em função do tempo após à alimentação

Table 7 - $\mathrm{N}-\mathrm{NH}_{3}$ concentration $\mathrm{mg} / 100 \mathrm{~mL}$ observed of in the ruminal fluid in function of the time after feeeding

\begin{tabular}{lrrrrr}
\hline T (horas) & \multicolumn{3}{c}{ Níveis de substituição (\%) } & \multirow{2}{*}{$\begin{array}{c}\text { Média } \\
\text { Levels of substitution (\%) }\end{array}$} \\
\cline { 2 - 4 } & $\mathrm{R} 25$ & $\mathrm{R} 50$ & $\mathrm{R} 75$ & $\mathrm{R} 100$ & \\
\hline 0 & 9,0 & 9,1 & 12,7 & 10,9 & 10,4 \\
2 & 10,8 & 7,8 & 7,2 & 10,2 & 9,0 \\
4 & 7,1 & 5,6 & 5,4 & 8,7 & 6,7 \\
6 & 5,5 & 5,3 & 5,1 & 6,5 & 5,6 \\
8 & 9,2 & 10,2 & 8,0 & 7,2 & 8,7 \\
Média & 8,3 & 7,6 & 7,7 & 8,7 & 8,1 \\
Average & & & & & \\
\hline
\end{tabular}

T = tempo após à alimentação; R25, R50, R75 e R100: respectivamente, níveis de farinha de varredura em substituição ao milho.

$T=$ time after feeding; R25, R50, R75 and R100: respectively, levels of substitution cassava by-product meal to corn.

Tabela 8 - Valores observados do pH ruminal em função do tempo após à alimentação

Table 8 - Observed values of ruminal $\mathrm{pH}$ in function of time after feeding

\begin{tabular}{lccccc}
\hline \multirow{2}{*}{$\begin{array}{l}\text { Thoras) } \\
\text { Thours) }\end{array}$} & \multicolumn{3}{c}{ Níveis de substituição (\%) } & Média \\
\cline { 2 - 4 } & R25 & R50 & R75 & R100 & \\
\hline 0 & 6,7 & 7,2 & 7,2 & 7,1 & 7,0 \\
2 & 6,3 & 6,3 & 6,4 & 6,2 & 6,3 \\
4 & 6,1 & 6,5 & 6,4 & 6,4 & 6,3 \\
6 & 6,2 & 6,4 & 6,4 & 6,6 & 6,4 \\
8 & 6,4 & 6,7 & 6,5 & 6,5 & 6,5 \\
Média & 6,3 & 6,6 & 6,5 & 6,5 & 6,5 \\
\hline
\end{tabular}

T = tempo após à alimentação; R25, R50, R75 e R100: respectivamente, níveis de farinha de varredura em substituição ao milho.

$T=$ time after feeding; R25, R50, R75 and R100: respectively, levels of substitution cassava by-product meal to corn.

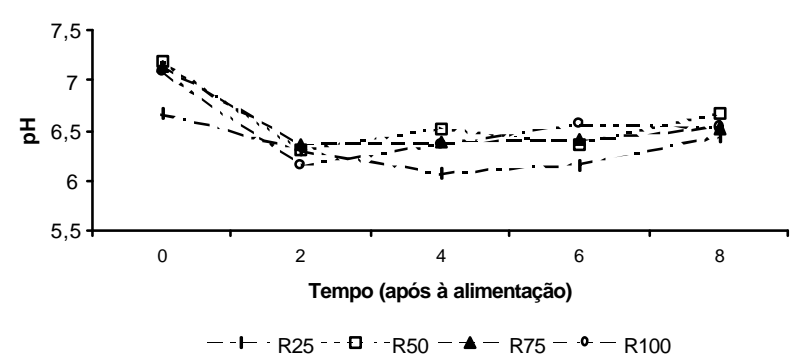

Figura 2 - Valores do $\mathrm{pH}$ do líquido ruminal dos ovinos em função do tempo após à alimentação para as rações experimentais $(25,50,75$ e $100 \%$ de substituição do MI pela FV).

Figura 2 - pHvalues of sheep ruminal fluid in function of time after feeding to experimental rations (25, 50, 75 and $100 \%$ substitution cassava by-product meal by corn). no tempo de 0 horas antes da alimentação. Também, o valor mínimo estimado para o $\mathrm{pH}$ ruminal foi em média de 6,2 às 0,6 horas após à alimentação, sendo que os valores observados indicam $\mathrm{pH}$ mínimo de 6,3 entre 2 e 4 horas após à alimentação.

Utilizando casca de mandioca, raspa de mandioca e farinha de varredura em substituição total ao milho, Zeoula et al. (2002) também não observaram diferença no $\mathrm{pH}$ do líquido ruminal de novilhos da raça Holandesa e com consumo restrito a $2 \%$ do peso vivo, sendo o valor máximo de $\mathrm{pH}$ de 6,8 (0 horas ou antes da alimentação) e o mínimo de 5,9 (4,5 horas após à alimentação) para a ração com FV. No entanto, no presente trabalho verificaram-se valores mais elevados de $\mathrm{pH}$ no líquido ruminal dos ovinos alimentados à vontade, que pode ser devido à metodologia utilizada (Ortolani, 1981). Entretanto, a digestibilidade da FDN foi semelhante entre as rações e segundo McCarthy et al. (1989), $\mathrm{pH}$ abaixo de 6,2 prejudica a degradação da fibra. Portanto, o valor médio observado do pH no líquido ruminal, para as rações experimentais, foi de 6,5 considerado bom para digestão de celulose pelos microrganismos do rúmen. $\mathrm{O}$ valor médio de digestibilidade da FDN foi de 53,9\% e o observado por Caldas Neto et al. (2001b), foi de 44,0\% para rações com FV. Também Valadares et al. (1997) alimentaram quatro novilhos zebus, à vontade, com dietas contendo $55 \%$ de volumoso e $45 \%$ de concentrado, com teor de PB variando de 7 a $14,5 \%$, e observaram que, entre todos os tratamentos e horários, os valores de $\mathrm{pH}$ variaram de 6,3 a 7,1.

\section{Conclusões}

A substituição do milho pela farinha de varredura não afetou o consumo, a digestibilidade dos nutrientes, o pH e a concentração de $\mathrm{N}$ amoniacal do líquido ruminal e os balanços de nitrogênio e de energia, em ovinos. Portanto, a farinha de varredura pode substituir em $100 \%$ o milho na ração desses animais.

\section{Literatura Citada}

BETT, V.; SANTOS, G.T.; AROEIRA, L.J.M. et al. Desempenho e digestibilidade in vivo de cordeiros alimentados com dietas contento canola em grão integral em diferentes formas. Revista Brasileira de Zootecnia, v.28, n.4, p.808-815, 1999.

CALDAS NETO, S.F. Digestibilidade parcial e total, parâmetros ruminais e degradabilidade de rações com mandioca e resíduos das farinheiras. Maringá: Universidade Estadual de Maringá, 1999. 66p. Dissertação (Mestrado em Zootecnia) - Universidade Estadual de Maringá, 1999. 
CALDAS NETO, S.F.; ZEOULA, L.M.; PRADO, I.N. et al. Mandioca e resíduos das farinheiras na alimentação de ruminantes: digestibilidade total e parcial. Revista Brasileira de Zootecnia, v.29, n.6, p.2099-2108, 2001b.

CAMERON, M.R.; KLUSMEYER, T.H.; LYNCH, G.L. et al. Effects of urea and starch on rumen fermentation, nutrient passage to the duodenum, and performance of cows. Journal of Dairy Science, v.74, n.4, p.1321-1336, 1991.

COELHO DA SILVA, J.F.; LEÃO, M.I. Fundamentos da nutrição de ruminantes. Piracicaba: Livroceres, 1979. 380p.

FICHTNER, S.S.; JARDIM, E.C.; LOPES, H.O.S. et al. Uso de raspa de mandioca para bezerros. In: REUNIÃO ANUALDA SOCIEDADE BRASILEIRA DE ZOOTECNIA, 27., 1990, Campinas. Anais... Campinas: Sociedade Brasileira de Zootecnia, 1990. p.38.

FREGADOLLI, F.L.; ZEOULA, L.M.; PRADO, I.N. et al. Efeito das fontes de amido e nitrogênio de diferentes degradabilidades ruminais. 1. Digestibilidades parcial e total. Revista Brasileira de Zootecnia, v.30, n.3, p.858-869, 2001.

GRANT, J.J. Influence of corn and sorghum starch on the in vitro kinetics of forage fiber digestion. Journal of Dairy Science, v.77, p.1563-1569, 1994.

HILL, K.J. Salivary and gastry secretions, in dukes physiology of domestic animals. Ithaca, New York: Comstock Publishing Associates, 1970.p.370.

JORGE, J.R.V.; ZEOULA, L.M.; PRADO, I.N. et al. Substituição do milho pela farinha de varredura ( Manihot esculenta, Crantz) na ração de bezerros Holandeses. 1. Desempenho e parâmetros sangüíneos. Revista Brasileira de Zootecnia, v.31, n.1, p.192-204. 2002a.

JORGE, J.R.V.; ZEOULA, L.M.; PRADO, I.N. et al. Substituição do milho pela farinha de varredura ( Manihot esculenta, Crantz) na ração de bezerros Holandeses. 2. Digestibilidade e valor energético. Revista Brasileira de Zootecnia, v.31, n.1, p.205-212, 2002b.

LAVEZZO, O.E.N.; LAVEZZO, W.; BURINI, R.C. Efeitos nutricionais da substituição parcial do farelo de soja, em dietas de ovinos. Comparação da digestibilidade aparente e balanço de nitrogênio com a cinética do metabolismo da n-glicina. Revista Brasileira de Zootecnia, v.25, n.2, p.282-297, 1996.

MARQUES, J. Avaliação da mandioca e seus resíduos industriais em substituição do milho na terminação de novilhas: desempenho e digestibilidade aparente in vivo. Maringá: Universidade Estadual de Maringá, 1999. 42p. Dissertação (Mestrado em Zootecnia) - Universidade Estadual de Maringá, 1999.

McCARTHY, R.D.; KLUZMEYER JR, T.H.; CLARK, J.H. et al. Effects of source of protein and carbohidrate on ruminal fermentation and passage of nutrients to the small intestine of lactating cows. Journal of Dairy Science, v.72, n.8, p.20022016, 1989.

NATIONAL RESEARCH COUNCIL - NRC. Nutrient requirements of sheep. 5.ed. Washington, D.C.: National Academy of Sciences, 1975. 41p.

NATIONAL RESEARCH COUNCIL. Nutrient requirements of beef cattle. Washington, D.C.: National Academy of Sciences, 1996. 242p.

NOCEK, J.E.; TAMINGA, S. Site of digestion of starch in the gastrointestinal tract of dairy cows and its effect on milk yield and composition. Journal of Dairy Science, v.74, n.10, p.3598-3629, 1991.

ØRSKOV, E.R. Starch digestion and utilization on ruminants. Journal of Animal Science, v.63, p.1624, 1986.

R. Bras. Zootec., v.32, n.2, p.491-502, 2003
ORTOLANI, E.L. Considerações técnicas sobre o uso da sonda esofágica na colheita do suco de rúmen de bovinos para mensuração do pH. Arquivo da Escola Veterinária, v.33, n.2, p.269-275, 1981.

OVERTON, T.R.; CAMERON, M.R.; ELLIOT, J.P. et al. Ruminal fermentation and passage of nutrients to the duodenum of lactating cows fed mixtures of corn and production. Journal of Dairy Science, v.78, p.1981-1998, 1995.

PEIXOTO, R.R.; WARNER, R.G. Avaliação da farinha de mandioca como componente de rações para terneiros leiteiros e desaleitamento precoce. Revista Brasileira de Mandioca, v.12, v.1/2, p.39-47, 1993.

PEREIRA, J.P. Utilização da raspa e resíduos industriais da mandioca na alimentação animal. Informe Agropecuário, v.13, n.145, p.28-41, 1987.

PEREIRA, J.R.A.; ROSSI, P. Manual prático de avaliação nutricional de alimentos. Piracicaba: Fundação de Estudos Agrários Luiz de Queiroz, 1995. 25p.

PRADO, I.N.; MARQUES, J.A.; BRANCO, A.F. et al. Avaliação da substituição do milho pela mandioca e seus resíduos na digestibilidade aparente em novilhas confinadas. Acta Scientiarum, v.21, n.3, p.677-682, 1999.

REYNOLDS, J.D.; SUTTON, J.D.; BEEVER, D.E. Effects of feeding starch to dairy cattle on nutrient availability and production. In: Recents advances in animal nutrition, p.105-134, 1997.

ROONEY, L.W.; PFLUGFELDER, R.L. Factors affecting starch digestibility with special emphasis on shorgum and corn. Journal of Animal Science, v.63, n.5, p.1607-1623, 1986.

SANTOS, F.A.P.; HUBER, J.T.; THEURER, C.B. et al. Comparison of barley and sorghum grain processed at different densities for lactating dairy cows. Journal of Dairy Science, v.80, p.2098-2103, 1997.

SATTER, L.D.; ROFFLER, R.E. Relationship between ruminal ammonia and nonprotein nitrogen utilization by ruminants. 1 . Development of a model for predicting nonprotein nitrogen utilization by catte. Jounal of Dariry Science, v.58, n.12, p.1880-1888, 1975.

SAUVANT, D.; CHAPOUTOT, P.; ARCHIMÈDES, H. La digestion des amidons par les ruminants et ses conséquences. INRA Prodution Animal, v.7, p.115-124, 1994.

SILVA, D.J.Análise de alimentos. 2.ed. Viçosa, MG: Universidade Federal de Viçosa, 1990. 166p.

SMITH, L.W.; GOERING, M.K.; GORDON, C.H. Relationship of forage compositions with rates of cell wall digestion and indigestibility of cell walls. Journal of Dairy Science, v.55, n.8, p.1140-1148, 1972.

SNIFFEN, C.J.; O'CONNOR, J.D.; Van SOEST, P.J. et al. A net carbohydrate and protein system for evaluating cattle diets II. Carbohydrate and protein availability. Journal of Animal Science, v.70, n.11, p.3562-3577, 1992.

SNIFFEN, C.J., BEVERLY, R.W., MOONEY, C.S. et al. Nutrient requirements versus supply in the dairy cow: strategies to account for variability.Journal of Dairy Science, v.76, n. 10, p.3160-3178, 1993.

STUMPF JR, W.; LOPEZ, J. Consumo e digestibilidade em dietas suplementadas com raiz de mandioca desidratada. Archivo Latino-americano de Produção Animal, v.2, n.1, p.59-68, 1994.

TIBO, G.C.; VALADARES FILHO, S.C.; COELHO DA SILVA, J.F. et al. Níveis de concentrado em dietas de novilhos mestiços F1 Simental x Nelore. 2: Balanço nitrogenado, eficiência microbiana e parâmetros ruminais. Revista Brasileira de Zootecnia, v.29, n.3, p.921-929, 2000. 
UNIVERSIDADE ESTADUAL DE VIÇOSA - UFV. SAEG Sistema de análise estatística e genética. Viçosa, MG: 1983. 68p. (Manual do usuário).

VALADARES, R.F.D.; GONÇALVES, L.C.; SAMPAIO I.B. et al. Níveis de proteína em dietas de bovino. 3: pH, amônia e eficiência microbiana. Revista Brasileira de Zootecnia, v.26, n.6, p.1264-1269, 1997.

Van SOEST, P.J. Nutritional ecology of the ruminant. New York: Cornell University Press, 1994. 476p.

VIEIRA, H.W. Digestão parcial e total da proteína em diferentes grupos genéticos de bovídeos. Viçosa, MG: Universidade Federal de Viçosa, 1984. 250p. Dissertação (Mestrado em Zootecnia) - Universidades Federal de Viçosa, 1984.

VILELA, E.R.; FERREIRA, M.E. Tecnologia de produção e utilização do amido da mandioca. Informe Agropecuário, v.13, n.145, p.69-73, 1987.

ZEOULA, L.M. Efeitos da fonte de amido, do processamento e da adição de uréia sobre a fermentação ruminal e digestão parcial e total em bovídeos. Viçosa, MG: Universidade Federal de Viçosa, 1990. 250p. Tese (Doutorado em Zootecnia) Universidade Federal de Viçosa, 1990.
ZEOULA, L.M.; CALDAS NETO, S.F.; BRANCO, A.F. et al. Mandioca e resíduos das farinheiras na alimentação de ruminantes: $\mathrm{pH}$, concentração de amônia e eficiência microbiana. Revista Brasileira de Zootecnia, v.31, n.3 suplemento, p.1582-1593, 2002.

ZEOULA, L.M.; MARTINS, A.S.; ALCALDE, C.R. et al. Solubilidade e degradabilidade ruminal do amido de diferentes alimentos. Revista Brasileira de Zootecnia, v.28, n.5, p.905912, 1999a.

ZEOULA, L.M.; PRADO, I.N.; CECATO, U. et al. Valor nutritivo de rações compostas de amido e de nitrogênio com alta e baixa degradabilidade ruminal. Revista Brasileira de Zootecnia, v.28, n.5, p.1159-1167, 1999b.

ZINN, R.A.; DEPETERS, E.J. Comparative feeding of tapioca pellets for feedlot cattle. Journal of Animal Science, v.69, n.12, p.4726-4733, 1991.

Recebido em: 29/10/02

Aceito em: 23/09/02 